\title{
Surgical treatment of liver metastases from non-colorectal non-neuroendocrine carcinomas
}

\author{
Astrid Bauschke ${ }^{1}$ (D) Annelore Altendorf-Hofmann ${ }^{1} \cdot$ Merten Homman $^{2} \cdot$ Thomas Manger $^{3} \cdot$ Jörg Pertschy $^{4}$. \\ Herry Helfritzsch ${ }^{5} \cdot$ Hubert Göbel $^{6}$. Utz Settmacher ${ }^{1}$
}

Received: 31 March 2021 / Accepted: 5 April 2021 / Published online: 20 April 2021

(c) The Author(s) 2021

\begin{abstract}
Introduction In the literature, results after surgical treatment of non-colorectal non-neuroendocrine liver metastases (NCNNLM) are reported that are often inferior to those from colorectal liver metastases. The selection of patients with favorable tumor biology is currently still a matter of discussion.

Materials/methods The retrospective data analysis was based on data that were collected for the multicenter study "Role of surgical treatment for non-colorectal liver metastases" in county Thuringia.

Results For the study, 637 patients were included from 1995 to 2018.5 and 10-year survival of R0 resected patients were $33 \%$ and 19\%, respectively. In the multi-variate analysis of the entire group, sex, timing, disease-free interval, number of metastases, R-classification as well as lymph node status of the primary lesion showed an independent statistical influence on the 5-year survival. In the group of R0 resected patients, disease-free interval, number of metastases and lymph node status of the primary lesion influenced the 5-year survival in the multi-variate analysis. In kidney malignancies, R-classification, timing and number of liver metastases were statistically significant in the multi-variate analysis of the 5-year survival, in mamma carcinomas only the R-classification.

Conclusion The Adam score identifies some risk factors which influence prognosis in most but not in all tumor entities. For kidney cancer and breast cancer it can be simplified.
\end{abstract}

Keywords Non-colorectal non-neuroendocrine liver metastases $\cdot$ Surgery $\cdot$ Survival

Astrid Bauschke

astrid.bauschke@med.uni-jena.de

1 Department of General, Visceral and Vascular Surgery, University Hospital Jena, Erlanger Allee 101, 07740 Jena, Germany

2 Department of General, Visceral Surgery, Zentralklinik Bad Berka, Robert-Koch-Allee 9, 99438 Bad Berka, Germany

3 Department of General, Visceral Surgery, SRH Wald-Klinikum Gera GmbH, Str. des Friedens 122, 07548 Gera, Germany

4 Department of General, Visceral and Vascular Surgery, Katholisches Krankenhaus Erfurt, Haarbergstraße 72, 99097 Erfurt, Germany

5 Thüringen-Kliniken "Georgius Agricola, Rainweg 68, 07318 Saalfeld, Germany

6 Clinical Cancer Registry Thuringia with Tumor Center e.V. Erfurt HELIOS Klinikum Erfurt GmbH, Haus 22, Nordhäuser Str. 74, 99089 Erfurt, Germany

\section{Introduction}

The effect of surgical therapy of non-colorectal non-neuroendocrine carcinomas is still under debate. Due to small incidence of liver metastases suitable for complete resection, only a few studies can give guidelines or recommendations for systemic or local therapy. Even in nationwide studies (Grimme et al. 2019; Ruys et al. 2011), the number of included patients remains small. Other than in colorectal carcinoma, in many solid carcinoma liver metastases are a predictor of more widespread disease. For many solid types of cancer effective hormone-, chemo- and immune-therapies exist. Often patients are presented to the surgeon when systemic therapies lead to progressive disease.

Most studies summarize a broad variety of cancer entities with differing prognosis to groups. Only for breast cancer (Feng et al. 2020), kidney cancer (Bauschke et al. 2021; Ruys et al. 2011), gastric cancer (Luo et al. 2019), and sarcoma (Grimme et al. 2019) exist a small number of studies 
with adequate sample size to help clinicians to make a decision for or against surgical therapy.

We present data from patients treated surgically in a German federal state.

\section{Materials/methods}

This retrospective data analysis is based on the data of the multi-center study "Role of surgical treatment of non-colorectal liver metastases in Thuringia". The study in human subjects was carried out with consent of the local ethics committee (ethical vote 5073-02/17) in accordance with national law and the Declaration of Helsinki of 1975 (in the current revised form).

From the five tumor centers in the country of Thuringia, we requested a list of all patients with OP codes 5-501.*, 5-502.* or 5-504.* (liver resection or liver transplantation, respectively) (Fritz 2013) in malignant primary tumors, except colorectal primaries, primary liver cancer, hilar cholangiocarcinoma and systemic diseases between 1995 and 2018. Data not found in the cancer registries of the five tumor centers were completed by contacting clinicians.

The participating hospitals were in addition to one university hospital, seven maximum care facilities and 12 other hospitals. Only patients with histologically confirmed liver metastases were included. Primary liver tumors, benign liver tumors, patients with direct invasion of the liver by peritoneal implants or by the primary tumor were excluded. Patients underwent routine staging using preoperative computed tomography scanning of the chest, abdomen, and pelvis.

Morphology was classified according to the manual of cancer registration (Stegmaier et al. 2019). In case of bilobar metastases smaller than $5 \mathrm{~cm}$, radiofrequency ablation was performed alone or in combination with liver resection. In case of combined resection and radiofrequency ablation, the procedure was classified as radiofrequency ablation. If all tumor locations had been successfully treated with radiofrequency ablation, it was classified as $\mathrm{R} 0$, in case of further remnant tumor locations as R2 situation.

The aim of surgery was always complete removal of all present tumor (R0 resection). Surgical options have been limited by intraoperative non-resectable primary tumors, but also by unknown diffuse liver metastases or non-resectable other tumor locations. In individual cases, regional lymphadenectomy was performed.

\section{Statistical methods}

All statistical analyses were performed using SPSS 26.0 (IBM, Chicago, IL, USA) software. Categorical variables were tested for independence using the Chi-squared test or
Fisher's exact test as indicated. Survival was calculated from the date of liver resection. Overall survival (patients' death irrespective of the cause of death) was used as the endpoint for estimating prognosis. The median follow-up time was calculated using the reverse Kaplan-Meier method. Survival curves were created using the Kaplan-Meier method, and the log-rank test was used to assess differences in survival. Significant and independent predictors of overall survival were identified by Cox proportional hazard analysis. The procedure was set to a threshold of 0.05 . Statistical significance was defined as a $p$ value $<0.05$ for all analyses.

\section{Results}

This study analyzed 637 patients who underwent treatment in 20 Thuringian hospitals from 1995 to 2018 . We analyzed location, morphology, and additionally 11 patient characteristics, also metastases, primary tumor lesion, liver metastases, surgical procedure, and individual hospital experience. $86 \%$ of the patients (546) underwent treatment in the nine transregional hospitals, $14 \%$ (91) in regional hospitals. 15 hospitals treated less than 40 patients, four hospitals between 40 and 100 patients, and the university hospital treated 213 patients.

In the hospitals that treated $<40$ patients, there were statistically significantly more less-than-radical procedures, limited resections, metastases following tumor free interval $<24$ months and non-resectable primary tumors $(p<0.001$ each).

Half of the 637 patients had extrahepatic tumor at the time of surgery. Only in $38 \%$ of the cases complete resection was accomplished. Details are shown in Table 1.

6 of the 26 different primary tumors (lung, ovary, kidney, stomach, breast, pancreas) are assigned to $86 \%$ of patients. In these, the proportion of R0 resections ranged between $16 \%$ (pancreas) and 64\% (lung).

In 75 patients (12\%), radiofrequency ablation of metastases was performed, sometimes in combination with liver resection. Complete macroscopic tumor resection was accomplished in 39 patients. In a total of 280 (44\%) patients, an R0 situation was thus achieved, in 24 (4\%) an R1 resection was performed. The primary tumor was non-resectable in 138 (22\%) patients, in the remaining 195 (31\%) patients, metastases were non-resectable (Table 2).

Most frequently (78\%), the diagnosis was adenocarcinoma, followed by squamous cell carcinoma (7\%), sarcomas and melanomas (5\% each), gastrointestinal stromal tumors (GIST) (2\%), and 3\% other tumors (three patients each with malignant granulosa cell tumor, unclassified carcinoma, two patients each with malignant mixed mullerian tumor, papillary carcinoma, pseudo sarcomatous carcinoma, undifferentiated carcinoma and one patient each with peripheral 
Table 1 Patients under study

\begin{tabular}{|c|c|c|c|c|}
\hline Category & Prognostic factor & Strata & Patients & $\%$ \\
\hline \multirow[t]{4}{*}{ Patient } & \multirow[t]{2}{*}{ Age } & $<60$ & 253 & 40 \\
\hline & & $\geq 60$ & 384 & 60 \\
\hline & \multirow[t]{2}{*}{ Sex } & Male & 303 & 48 \\
\hline & & Female & 334 & 52 \\
\hline \multirow[t]{14}{*}{ Hepatic metastases } & \multirow[t]{2}{*}{ Timing } & Metachronous & 355 & 56 \\
\hline & & Synchronous & 282 & 44 \\
\hline & \multirow[t]{3}{*}{ Disease-free interval } & $<12$ months & 345 & 54 \\
\hline & & 12-24 months & 71 & 11 \\
\hline & & $>24$ months & 221 & 35 \\
\hline & \multirow[t]{2}{*}{ Number } & Solitary & 262 & 41 \\
\hline & & Multiple & 375 & 59 \\
\hline & \multirow[t]{2}{*}{ Size } & $<5 \mathrm{~cm}$ & 482 & 76 \\
\hline & & $>5 \mathrm{~cm}$ & 155 & 24 \\
\hline & \multirow[t]{2}{*}{ Extrahepatic disease } & Present & 320 & 50 \\
\hline & & Absent & 317 & 50 \\
\hline & \multirow[t]{3}{*}{ Adam risk score } & Low & 136 & 22 \\
\hline & & Intermediate & 372 & 58 \\
\hline & & High & 129 & 20 \\
\hline \multirow[t]{5}{*}{ Hepatectomy } & \multirow[t]{2}{*}{ Extent of liver resection } & Limited & 494 & 78 \\
\hline & & Major & 143 & 22 \\
\hline & \multirow[t]{3}{*}{ Margin of liver resection } & R0 & 280 & 44 \\
\hline & & $\mathrm{R} 1$ & 24 & 4 \\
\hline & & $\mathrm{R} 2$ & 333 & 52 \\
\hline \multirow[t]{3}{*}{ Primary tumor } & \multirow[t]{3}{*}{$\mathrm{N}$-category of primary tumor } & $\mathrm{N}-$ & 289 & 45 \\
\hline & & $\mathrm{N}+$ & 210 & 33 \\
\hline & & Not removed & 138 & 22 \\
\hline \multirow[t]{3}{*}{ Hospital } & \multirow[t]{3}{*}{ Number of patients } & University & 213 & 33 \\
\hline & & $\geq 40$ & 249 & 39 \\
\hline & & $<40$ & 175 & 28 \\
\hline
\end{tabular}

neuro-ectodermal tumor, choroid carcinoma, mixed germcell carcinoma, yolk sac carcinoma, embryonic carcinoma, adeno-squamous carcinoma or anaplastic carcinoma.

\section{Morbidity/30-day mortality}

Among the 346 limited procedures, there were 254 atypical resections and 66 radiofrequency ablations. Among atypical resections, one hemorrhage and one liver abscess were documented. Another liver abscess required treatment after radiofrequency ablation. In the remaining 289 cases, 60 complications were recorded resulting in $21 \%$ morbidity (Clavien II-V). Seven of these patients died post-operatively, four after $\mathrm{R} 0$, and three after $\mathrm{R} 2$ resection.

\section{Long-term survival}

The median follow-up period in all patients was 107 months.

The 5- and 10-year survival rates in all patients were $18 \%$ and $9 \%$, respectively, median survival time was 16 months.
So far, 86 patients have survived liver surgery longer than five years and 26 patients have survived the procedure for longer than 10 years. Primaries were nine breast cancers, four GISTs, four kidney tumors, two adenocarcinomas of stomach or ovary, one squamous cell carcinoma of each lung, esophagus, larynx, as well as one malignant melanoma of the skin, and one leiomyosarcoma of the small intestine.

If all detectable tumor was removed by radiofrequency ablation, the 5-year survival rate was not significantly different from that after R0 resection. After R2 procedures, the survival rates were almost identical for resection and radiofrequency ablation.

The survival rates in all 637 cases have been pair-wise statistically significantly different, depending on the number of patients treated per hospital. If one considers only the $241 \mathrm{R} 0$ resected patients, survival rates are almost identical.

With respect to the individual locations of the primary tumor, the 5-year survival rate was between $0 \%$ (pancreas) and $30 \%$ (kidney) (Table 3). 
Table 2 R-classification according to location of the primary tumor

\begin{tabular}{|c|c|c|c|c|c|c|c|c|c|c|c|}
\hline \multirow{2}{*}{$\begin{array}{l}\text { Location } \\
\text { Esophagus }\end{array}$} & \multirow{2}{*}{$\begin{array}{c}\text { Patients } \\
17\end{array}$} & \multicolumn{2}{|l|}{ R0 } & \multicolumn{2}{|l|}{$\mathrm{R} 1$} & \multicolumn{2}{|l|}{$\mathrm{R} 2$} & \multicolumn{2}{|c|}{$\begin{array}{l}\text { Thermo- } \\
\text { ablation, } \\
\text { R0 }\end{array}$} & \multicolumn{2}{|c|}{$\begin{array}{l}\text { Thermo- } \\
\text { ablation, } \\
\text { R2 }\end{array}$} \\
\hline & & 6 & $35 \%$ & 0 & $0 \%$ & 9 & $53 \%$ & 0 & $0 \%$ & 2 & $12 \%$ \\
\hline Stomach & 94 & 44 & $47 \%$ & 4 & $4 \%$ & 33 & $35 \%$ & 10 & $11 \%$ & 3 & $3 \%$ \\
\hline Small intestine & 19 & 10 & $53 \%$ & 0 & $0 \%$ & 8 & $42 \%$ & 0 & $0 \%$ & 1 & $5 \%$ \\
\hline Anus, anal canal & 5 & 4 & $80 \%$ & 0 & $0 \%$ & 1 & $20 \%$ & 0 & $0 \%$ & 0 & $0 \%$ \\
\hline Pancreas & 143 & 23 & $16 \%$ & 3 & $2 \%$ & 110 & $77 \%$ & 5 & $3 \%$ & 2 & $1 \%$ \\
\hline Ear, nose, throat area & 5 & 3 & $60 \%$ & 0 & $0 \%$ & 1 & $20 \%$ & 0 & $0 \%$ & 1 & $20 \%$ \\
\hline Lung & 22 & 14 & $64 \%$ & 0 & $0 \%$ & 5 & $23 \%$ & 1 & $5 \%$ & 2 & $9 \%$ \\
\hline Thymus & 1 & 0 & $0 \%$ & 0 & $0 \%$ & 1 & $100 \%$ & 0 & $0 \%$ & 0 & $0 \%$ \\
\hline Bones & 1 & 0 & $0 \%$ & 0 & $0 \%$ & 1 & $100 \%$ & 0 & $0 \%$ & 0 & $0 \%$ \\
\hline Skin & 11 & 5 & $45 \%$ & 0 & $0 \%$ & 4 & $36 \%$ & 1 & $9 \%$ & 1 & $9 \%$ \\
\hline Retroperitoneum & 7 & 2 & $29 \%$ & 0 & $0 \%$ & 4 & $57 \%$ & 1 & $14 \%$ & 0 & $0 \%$ \\
\hline Peripheral soft tissue & 2 & 1 & $50 \%$ & 0 & $0 \%$ & 1 & $50 \%$ & 0 & $0 \%$ & 0 & $0 \%$ \\
\hline Mamma & 117 & 46 & $39 \%$ & 4 & $3 \%$ & 37 & $32 \%$ & 14 & $12 \%$ & 16 & $14 \%$ \\
\hline Cervix/uterus & 19 & 9 & $47 \%$ & 2 & $11 \%$ & 7 & $37 \%$ & 0 & $0 \%$ & 1 & $5 \%$ \\
\hline Gall bladder/bile ducts & 5 & 2 & $40 \%$ & 1 & $20 \%$ & 1 & $20 \%$ & 1 & $20 \%$ & 0 & $0 \%$ \\
\hline Ovary & 38 & 11 & $29 \%$ & 4 & $11 \%$ & 18 & $47 \%$ & 1 & $3 \%$ & 4 & $11 \%$ \\
\hline Prostate & 8 & 1 & $13 \%$ & 1 & $13 \%$ & 5 & $63 \%$ & 0 & $0 \%$ & 1 & $13 \%$ \\
\hline Testes & 4 & 1 & $25 \%$ & 0 & $0 \%$ & 3 & $75 \%$ & 0 & $0 \%$ & 0 & $0 \%$ \\
\hline Kidney & 70 & 40 & $57 \%$ & 4 & $6 \%$ & 21 & $30 \%$ & 3 & $4 \%$ & 2 & $3 \%$ \\
\hline Renal pelvis & 4 & 2 & $50 \%$ & 0 & $0 \%$ & 2 & $50 \%$ & 0 & $0 \%$ & 0 & $0 \%$ \\
\hline Ureter & 1 & 0 & $0 \%$ & 0 & $0 \%$ & 1 & $100 \%$ & 0 & $0 \%$ & 0 & $0 \%$ \\
\hline Urinary bladder & 6 & 3 & $50 \%$ & 1 & $17 \%$ & 2 & $33 \%$ & 0 & $0 \%$ & 0 & $0 \%$ \\
\hline Eye & 18 & 9 & $50 \%$ & 0 & $0 \%$ & 7 & $39 \%$ & 2 & $11 \%$ & 0 & $0 \%$ \\
\hline Thyroid gland & 4 & 2 & $50 \%$ & 0 & $0 \%$ & 2 & $50 \%$ & 0 & $0 \%$ & 0 & $0 \%$ \\
\hline Adrenal gland & 4 & 3 & $75 \%$ & 0 & $0 \%$ & 1 & $25 \%$ & 0 & $0 \%$ & 0 & $0 \%$ \\
\hline Unknown primary tumor & 12 & 0 & $0 \%$ & 0 & $0 \%$ & 12 & $100 \%$ & 0 & $0 \%$ & 0 & $0 \%$ \\
\hline Total & 637 & 241 & $38 \%$ & 24 & $4 \%$ & 297 & $47 \%$ & 39 & $6 \%$ & 36 & $6 \%$ \\
\hline
\end{tabular}

For 64 radically resected patients (R0/R1) and patients with breast carcinoma, the 5- and 10-year overall survival rates were $46 \%$ and $29 \%$, respectively, for ovarian cancer liver metastases $41 \%$ and $21 \%$, respectively, for kidney cancer liver metastases $39 \%$ and $18 \%$, and for gastric adenocarcinoma $17 \%$ and $7 \%$, respectively (Fig. 1). None of our patients with pancreatic adenocarcinoma survived 5 years, the median survival time for the 23 R0-resected patients was 23 months.

Patients with liver metastases from breast cancer had a better 5- and 10-year survival than from lung malignancies and gastrointestinal tumors $(p=0.005)$. Patients with liver metastases from adenocarcinomas of the pancreas had a significantly poorer survival than all other malignancies (Fig. 2). Liver metastases from breast cancer had a better survival than from gastrointestinal tumors and lung malignancies ( $p=0.026$ ) (Table 3$)$. For breast cancer, one needs to consider that immunotherapy and chemotherapy may influence the prognosis in the metastatic stage markedly.
Still, patients with breast cancer are investigated separately by some authors, as with the introduction of immunotherapy and chemotherapy the prognosis was markedly improved.

Location only does not always provide for homogenous groups. For breast and kidney, only metastases from adenocarcinomas were observed. In the esophagus, there were half adenocarcinomas or squamous cell carcinomas each, respectively; in the stomach in addition to adenocarcinomas also $11 \%$ GIST and $2 \%$ sarcomas.

In our study, there is a statistically significant difference in survival between urinary bladder, ureter, and renal pelvis versus ovary $(p=0.012)$ and versus kidney $(p=0.017)$ (Fig. 3).

The highest 5-year survival rates (75\%) were achieved in GIST, the lowest in squamous cell carcinoma (8\%). Long-term survival of the 16 GISTs was statistically significantly better than that of all other groups. Sarcomas had a statistically significantly better long-term survival than 
Table 3 5-, 10-year survival rates according to location and morphology of the primary tumor

\begin{tabular}{|c|c|c|c|c|c|}
\hline $\begin{array}{l}\text { Study popula- } \\
\text { tion }\end{array}$ & Patients & $\%$ & $\begin{array}{l}\text { 5-year } \\
\text { survival } \\
(\%)\end{array}$ & $\begin{array}{l}\text { 10-year } \\
\text { survival } \\
(\%)\end{array}$ & $\begin{array}{l}\text { Median } \\
\text { survival } \\
\text { (months) }\end{array}$ \\
\hline All patients & 637 & 100 & 18 & 9 & 16 \\
\hline \multicolumn{6}{|l|}{ Location } \\
\hline Pancreas & 143 & 22 & 0 & 0 & 8 \\
\hline Lung & 22 & 4 & 8 & 8 & 19 \\
\hline Other $\mathrm{PT}^{\mathrm{a}}$ & 87 & 14 & 13 & 6 & 18 \\
\hline $\begin{array}{l}\text { Esophagus/ } \\
\text { stomach/ } \\
\text { small intes- } \\
\text { tine }\end{array}$ & 130 & 20 & 20 & 11 & 16 \\
\hline $\begin{array}{l}\text { Female geni- } \\
\text { tals }\end{array}$ & 57 & 9 & 23 & 9 & 27 \\
\hline Mamma & 117 & 18 & 29 & 18 & 31 \\
\hline $\begin{array}{l}\text { Kidney/renal } \\
\text { pelvis }\end{array}$ & 82 & 13 & 30 & 10 & 23 \\
\hline \multicolumn{6}{|l|}{ Morphology } \\
\hline $\begin{array}{l}\text { Squamous } \\
\text { cell }\end{array}$ & 43 & 7 & 8 & 8 & 8 \\
\hline Melanoma & 29 & 5 & 11 & 11 & 16 \\
\hline $\begin{array}{l}\text { Adenocarci- } \\
\text { noma }\end{array}$ & 499 & 78 & 16 & 8 & 15 \\
\hline $\begin{array}{c}\text { Other mor- } \\
\text { phologie }\end{array}$ & 21 & 3 & 18 & 9 & 12 \\
\hline Sarcoma & 29 & 5 & 30 & 14 & 36 \\
\hline Stromal GIST & 16 & 2 & 75 & 39 & 104 \\
\hline
\end{tabular}

${ }^{a}$ Other PT primary tumor: unknown primary tumor-12, adrenal gland -4 , thyroid gland -4 , eye -18 , testes -4 , prostate -8 , gall bladder/bile ducts -5 , peripheral soft tissue -2 , retroperitoneum -7 , skin -11 , bones -1 , thymus -1 , ear nose and throat area- 5 , anus and anal canal-5

squamous cell carcinomas and adenocarcinomas. The difference between squamous cell carcinomas and sarcomas or adenocarcinomas, too, was statistically significant, but not the difference between malignant melanomas and adenocarcinomas or squamous cell carcinomas (Table 3, Fig. 4). In malignant melanomas there was no statistically significant difference in long-term survival between 18 choroid melanomas and 11 skin melanomas (Fig. 5).

While in the univariate analysis of all 637 patients, all investigated factors had a statistically significant impact on the 5-year survival; in the multivariate analysis only sex, timing, disease-free interval, number of metastases, R-classification, lymph node status of the primary lesion as well as remaining primary lesion had an independent statistically significant impact on the 5-year survival. In the $241 \mathrm{R} 0$ resected patients, disease-free interval, number of metastases, and lymph node status of the primary lesion showed an independent statistically different impact on survival in the multivariate analysis (Table 4).

We further investigated the prognostic factors for longterm survival in adenocarcinomas, gastrointestinal carcinomas, breast cancers and kidney carcinomas. The respective statistically significant prognostic factors were included in the multivariate analysis.

In the multivariate analysis of all 499 adenocarcinomas, sex, timing, disease-free interval, number of metastases, and R-classification had a statistically significant impact. Analysis of the 94 gastrointestinal adenocarcinomas showed that only age had a statistically significant impact ( $p=0.036$ ) on the observed 5-year survival (Table 5). In liver metastases from breast cancer only the R-classification had an independent statistically significant impact on the 5-year survival. In kidney carcinomas, the number of liver metastases, the interval between resection of the primary lesion and the diagnosis of liver metastases as well as the R-classification had an independent statistically significant impact on the 5-year survival (Table 6).

\section{Discussion}

Non-colorectal non-neuroendocrine liver metastases are far from being a homogenous group. A resilient search for prognostic factors requires a minimum number of patients. Thus, most studies are published from highly specialized hospitals or a group of them. In the last years, liver surgery, limited resections in particular, can be performed with low morbidity and mortality (Table 7). In consequence, smaller hospitals, too, perform liver resections. Yet, surgical decision making in rare entities, such as non-colorectal liver metastases is extremely complex while guidelines for these are lacking.

We studied surgically treated cases of non-colorectal non-neuroendocrine liver metastases from all hospitals in a well-defined geographical region. As expected, there were statistically significant differences between small and large hospitals with respect to case mix and treatment as well as in 5- and 10-year survival rates for all cases in the univariate analyses. In the multivariate analyses, however, we observed no statistically significant influence of the hospital category on 5- and 10-year survival rates.

5- and 10-year rates for observed survival were $18 \%$ and $9 \%$ for all cases, respectively, and $33 \%$ and $19 \%$, respectively for R0-resected cases. These survival rates are similar to those in non-small cell lung carcinoma (Lu et al. 2019). 5- and 10-year rates for observed survival in the literature vary from 19 to $57 \%$ and $23 \%$ to $31 \%$, respectively (Table 7). These differences are mainly due to case mix in the studies. Patients with breast cancer were included in 5\% (Sano et al. 

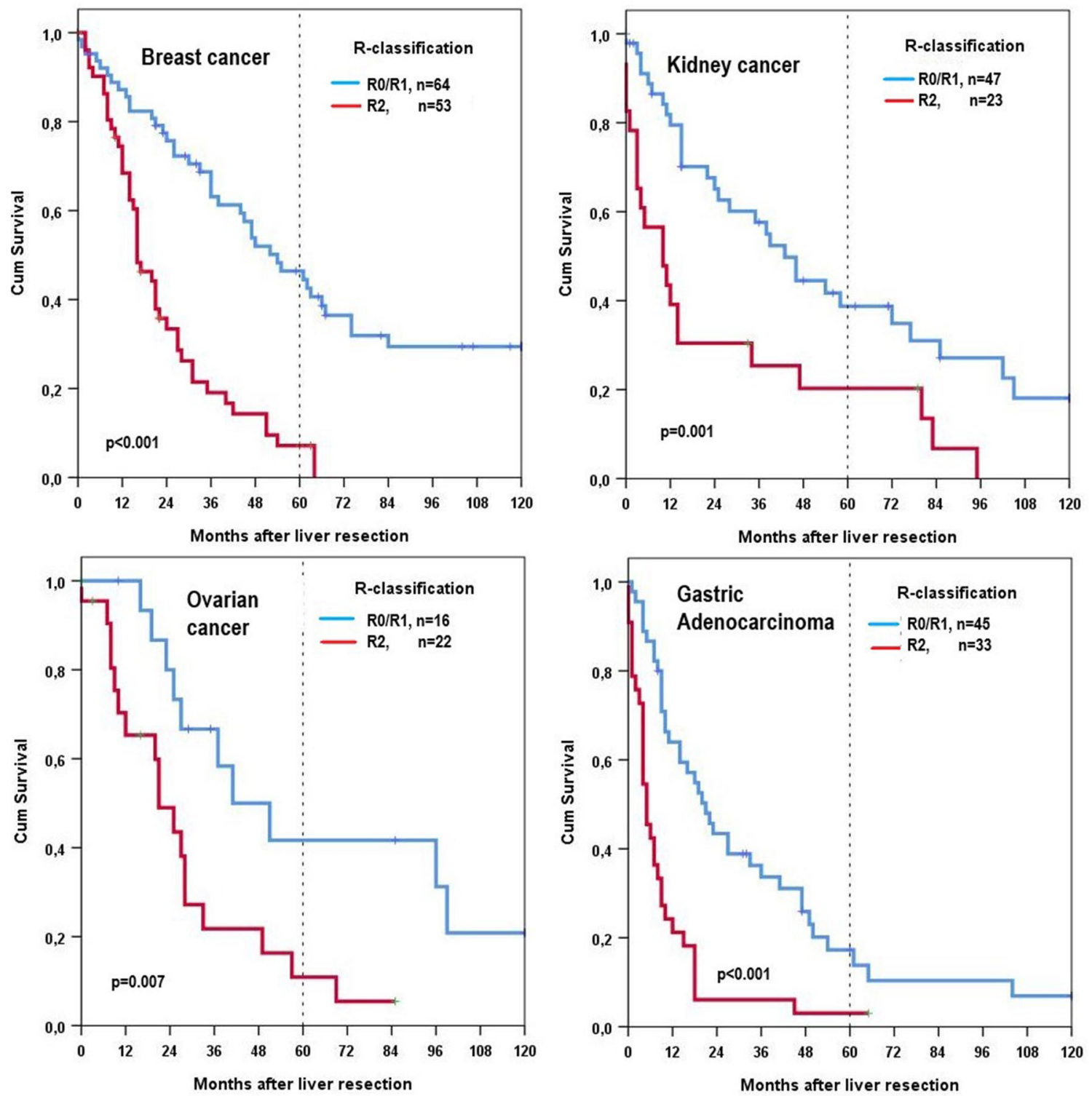

Fig. 1 Overall survival of patients with breast cancer, kidney cancer, ovarian cancer, and adenocarcinoma of the stomach

(2018) to 61\% (Bohlok et al. (2020), but most studies do not provide detailed information on tumor sites. Some studies combine primaries of ovary, kidney, urinary bladder, ureter, testis, and prostate to "genitourinary cancer" (Bohlok et al. 2020; Lendoire et al. 2007; Schiergens et al. 2016; Takemura et al. 2013; Yedibela et al. 2005). These groups include cancers with different prognosis. In our study, there is a statistically significant difference in survival between urinary bladder, ureter, and renal pelvis versus ovary $(p=0.012)$ and versus kidney $(p=0.017)$. We saw no primaries of the testis because metastases from these tumors are mainly treated with systemic therapy.

The median survival time of only 13 months for R0-resected patients with pancreatic adenocarcinoma is in agreement with other studies (Andreou et al. 2018; Hackert et al. 2017; Tachezy et al. 2016).

The percentage of GIST with excellent prognoses varies in studies with more than 100 patients from 0 to $18 \%$, the percentage of sarcoma with good prognoses from $<1$ to $23 \%$. Since 2005 , all GISTs are primarily treated by protein 
Fig. 2 Overall survival dependent on location of the primary

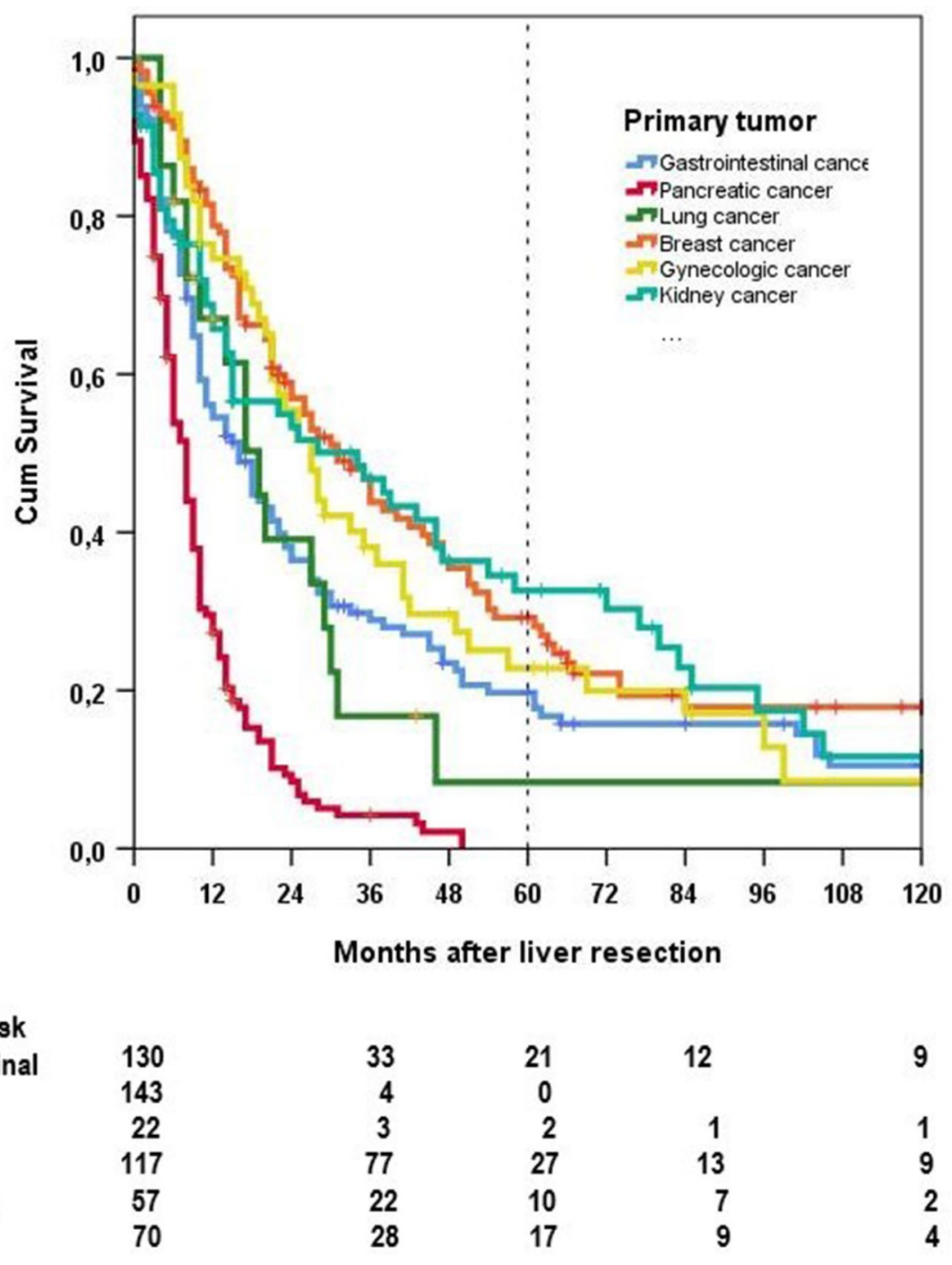

Patients at risk

Gastrointestinal

Pancreatic

Lung

Breast

Gynecologic

Kidney kinase inhibitors. Surgery is only indicated when systemic therapy fails.

In addition to differences in primary tumor sites and histological types, the lowest R0-rate is $62 \%$, the highest $93 \%$. In our study, residual tumor after liver resection was the most important negative factor for 5-year survival in all patients and in the subgroups of adenocarcinoma, kidney cancers, and breast cancers.

A short interval between diagnosis of the primary tumor and liver metastases also resulted independently in poorer 5 -year survival. We saw in $65 \%$ of patients a tumor free interval of less than 24 months, others saw $50 \%$ or $51 \%$ (Bohlok et al. 2020; Holzner et al. 2018; Slotta et al. 2014).
Multiple liver metastases were the third factor having a negative impact on 5-year survival. In our study, $41 \%$ of patients had solitary liver metastases; in the literature, the percentage varies between 46 and 62\% (Bohlok et al. 2020; Hoffmann et al. 2015; Lendoire et al. 2007; Sano et al. 2018; Takemura et al. 2013; Yedibela et al. 2005).

Male sex was a negative prognostic factor in all patients and in adenocarcinoma. Only in R0-resected cases influenced positive lymph nodes of the primary tumor the 5-year survival independently and statistically significant.

R-classification was in several studies (Adam et al. 2006; Groeschl et al. 2012; Holzner et al. 2018; Lendoire et al. 2007; Lucchese et al. 2018; Schiergens et al. 2016; Weitz 
Fig. 3 Overall survival of patients with genitourinary cancer

\section{Patients at risk Kidney \\ Ovary \\ Prostate \\ Urinary bladder, ureter, renal pelvis}

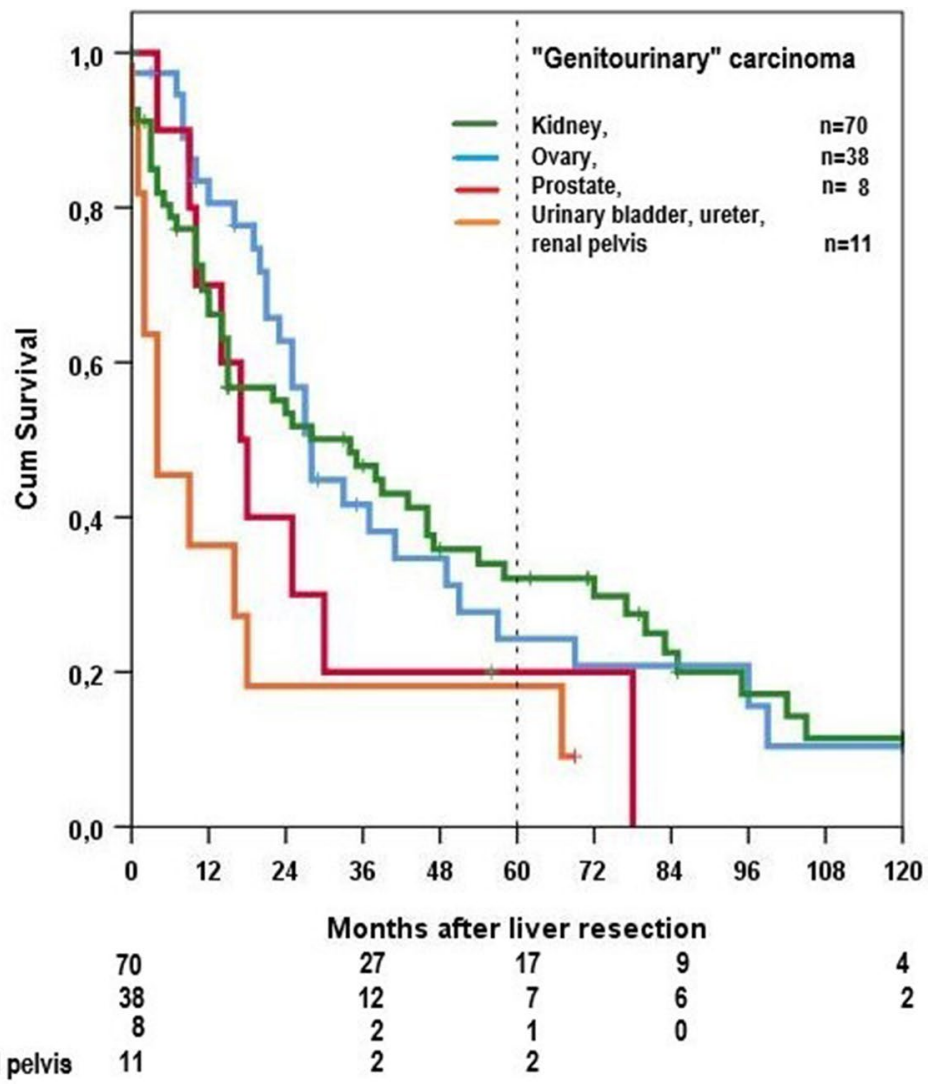

et al. 2005) found to be an independent statistically significant factor for overall survival, as well as disease-free survival (Groeschl et al. 2012; Hoffmann et al. 2015; Holzner et al. 2018; Lendoire et al. 2007; Sano et al. 2018; Schmelzle et al. 2010; Weitz et al. 2005). In two studies the number of liver metastases was an independent statistically significant factor for overall survival (Sano et al. 2018; Schiergens et al. 2016).

In contrast to other studies, we did not find an independent statistically significant impact of extrahepatic tumor (Adam et al. 2006; Lucchese et al. 2018; O'rourke et al. 2008; Sano et al. 2018; Schiergens et al. 2016), lymphatic vessel invasion (Groeschl et al. 2012), type of liver resections (Adam et al. 2006), or diameter of metastases (Groeschl et al. 2012; O'rourke et al. 2008) on 5-year survival.

For breast cancer one needs to consider tumor biology, such as expression of progesterone and estrogen, HER2 receptor status and systemic treatment with hormone therapy, chemotherapy, and treatment with monoclonal antibodies to influence the prognosis in the metastatic stage markedly (Dittmar et al. 2013). In the present study, we saw for all 117 patients with breast cancer 5- and 10-year survival rates of $29 \%$ and $18 \%$, respectively, for 64 radically resected patients (R0/R1) 5- and 10-year overall survival rates were $46 \%$ and $29 \%$, respectively. These rates are similar to results in colorectal liver metastases. Yet even studies with control groups reach unequivocal conclusions on the benefit of resecting liver metastases from breast cancer (Millen et al. 2021; Sadot et al. 2016).

Similar results to breast cancer were achieved in radically resected ovarian cancer liver metastases with 5- and 10 -year survival rates of $41 \%$ and $21 \%$, respectively, and kidney cancer liver metastases with 5- and 10-year overall survival rates of $39 \%$ and $18 \%$, respectively. These results are confirmed by others (Bauschke et al. 2021; Zhuo et al. 2020).

Most studies on liver resection in gastric carcinoma include Chinese or Japanese patients. In series with more than 20 resected patients, 5-year overall survival rates vary between 10 and 40\% (Kataoka et al. 2017). We found 5- and 
Fig. 4 Overall survival dependent on histology

\section{Patients at risk GIST Sarcoma Malignant Melanoma Adenocarcinoma Squamous cell carcinoma}

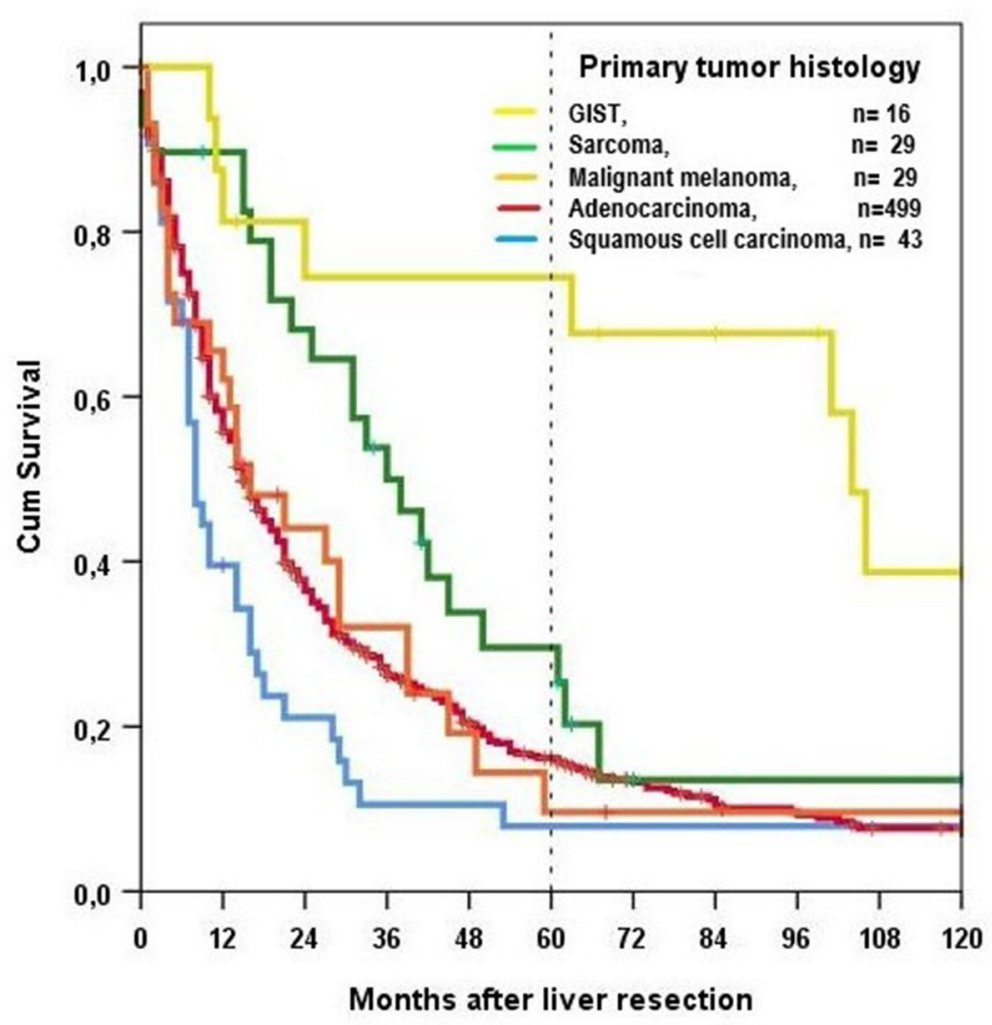

16

29

29

499

43

11
14
8
113
4

$\begin{array}{rr}11 & 9 \\ 7 & 1 \\ 2 & 1 \\ 61 & 31 \\ 3 & 3\end{array}$

10 -year overall survival rates of $17 \%$ and $7 \%$, respectively for radically resected liver metastases of gastric adenocarcinoma. In a recently published paper, Jagric and Horvat (2020) found that synchronous liver resection in gastric cancer patients is safe and offers significant survival benefit compared to chemotherapy alone. Patients might expect similar long-term survival as patients with stages III and IV gastric cancer without liver metastases and $\mathrm{R} 0$ resection (Jagric and Horvat 2020).

For all other primaries in our study, sample sizes were too small to draw reliable conclusions by use of survival analysis. To overcome this problem, Adam et al. (2006) published a risk score for non-colorectal non-neuroendocrine liver metastases of mixed primaries which differentiates three groups (low, intermediate, and high risk) dependent on six factors in 2006. In our study as well as in others (Hoffmann et al. 2015; Lendoire et al. 2007; Sano et al. 2018), this score led to pair-wise statistically different prognostic groups. In our study, there were no patients with high-risk breast carcinoma. Moreover, in the multivariate analysis for breast cancer, only the R-classification had an independent statistically significant impact on 5-year survival. 
Fig. 5 Overall survival of patients with malignant melanoma

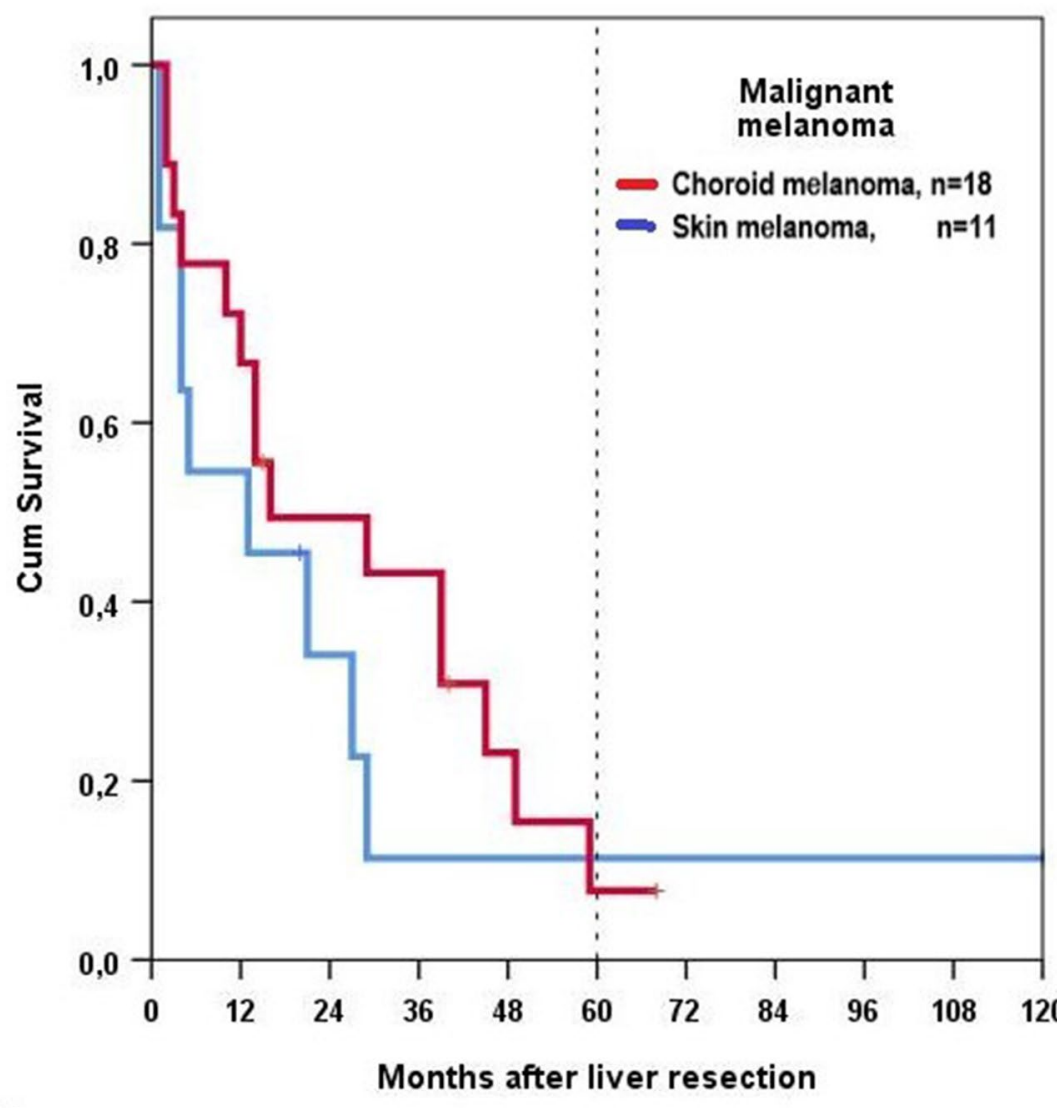

Patients at risk

Choroid melanoma

Skin melanoma
7
1
1

1
1

\section{Conclusion}

In studies investigating mixed primaries and different histological tumor entities, the most important factor for longterm survival is the case mix. We saw that complete resection of all tumor lesions at the time of liver resection leads to significantly better survival than incomplete procedures in most primaries. For R0-resected patients, we saw 5- and 10 -year survival rates of $33 \%$ and $19 \%$, respectively. In cases of bilobar metastases, a combination of surgical resection and ablation leads to similar results.
The Adam score (Adam et al. 2006) identifies some risk factors which influence prognosis in most but not in all tumor entities. For kidney cancer and breast cancer it can be simplified.

As long as it is impossible to initiate studies with uniform inclusion criteria and sample sizes similar to those published for colorectal cancer metastases the value of liver resection for patients with non-colorectal non-neuroendocrine liver metastases will remain an issue under discussion. 
Table 4 Uni- and multi-variate analyses of all patients and of the R0 resected

\begin{tabular}{|c|c|c|c|c|c|}
\hline \multicolumn{2}{|l|}{ All patients, $n=637$} & \multicolumn{2}{|l|}{ Univariate } & \multicolumn{2}{|l|}{ Multivariate } \\
\hline Prognostic factor & Strata & Significance & $\operatorname{Exp}(B)(95 \%$ CI $)$ & Significance & $\operatorname{Exp}(B)(95 \% \mathrm{CI})$ \\
\hline Age & & 0.007 & $1.012(1.003-1.021)$ & 0.108 & $1.007(0.998-1.016)$ \\
\hline Sex & Female/male & 0.000 & $1.615(1.349-1.933)$ & 0.005 & $1.315(1.087-1.591)$ \\
\hline Timing & Metachronous/synchronous & 0.000 & $2.331(1.942-2.798)$ & 0.006 & $1.418(1.104-1.822)$ \\
\hline Disease-free interval & $>24$ months/0-24 months & 0.000 & $1.990(1.647-2.404)$ & 0.047 & $1.304(1.004-1.695)$ \\
\hline Number of liver metastases & Solitary/multiple & 0.000 & $1.990(1.647-2.404)$ & 0.000 & $1.525(1.233-1.887)$ \\
\hline Size of lesion & $\leq 5 \mathrm{~cm} />5 \mathrm{~cm}$ & 0.008 & $0.750(0.607-0.926)$ & 0.967 & $0.995(0.779-1.270)$ \\
\hline Extrahepatic disease & Absent/present & 0.000 & $0.606(0.506-0.726)$ & 0.651 & $1.056(0.833-1.340)$ \\
\hline Extent of liver resection & Limited/major & 0.000 & $1.514(1.215-1.887)$ & 0.819 & $1.031(0.793-1.341)$ \\
\hline Margin of liver resection & $\mathrm{R} 0 / \mathrm{R} 1-2$ & 0.000 & $2.436(2.002-2.965)$ & 0.000 & $1.829(1.415-2.364)$ \\
\hline \multirow[t]{3}{*}{$\mathrm{N}$-category of primary tumor } & $\mathrm{N} 0 / \mathrm{N}+/$ primary tumor not removed & & & 0.011 & \\
\hline & & 0.001 & $1.427(1.161-1.755)$ & $\mathbf{0 . 0 2 3}$ & $1.283(1.035-1.589)$ \\
\hline & & 0.000 & $3.379(2.666-4.282)$ & 0.009 & $1.497(1.104-2.031)$ \\
\hline \multirow[t]{3}{*}{ Number of patients per hospital } & $\begin{array}{l}\text { University } />40 \text { patients } / \leq 40 \\
\text { patients }\end{array}$ & & & 0.530 & \\
\hline & & 0.002 & $1.396(1.125-1.733)$ & 0.268 & $1.151(0.898-1.475)$ \\
\hline & & 0.000 & $1.777(1.415-2.233)$ & 0.386 & $1.130(0.857-1.489)$ \\
\hline \multicolumn{6}{|l|}{$\mathrm{R} 0, n=241$} \\
\hline Sex & Female/male & 0.003 & $1.618(1.172-2.233)$ & 0.056 & $1.385(0.991-1.935)$ \\
\hline Timing & Metachronous/synchronous & $\mathbf{0 . 0 0 0}$ & $2.251(1.618-3.132)$ & 0.083 & $1.424(0.955-2.125)$ \\
\hline Disease-free interval & $>24$ months/0-24 months & 0.000 & $2.373(1.668-3.375)$ & 0.015 & $1.692(1.108-2.583)$ \\
\hline Number of liver metastases & Solitary/multiple & 0.019 & $1.490(1.069-2.077)$ & 0.016 & $1.517(1.082-2.127)$ \\
\hline $\mathrm{N}$-category of primary tumor & $\mathrm{N} 0 / \mathrm{N}+$ & 0.001 & $1.702(1.230-2.354)$ & 0.020 & $1.489(1066-2.081)$ \\
\hline
\end{tabular}

Bold indicates $p<0.005$

Table 5 Uni- and multi-variate analyses of patients with adenocarcinomas or gastrointestinal adenocarcinomas

\begin{tabular}{|c|c|c|c|c|c|}
\hline \multicolumn{2}{|l|}{ Adenocarcinoma, $n=499$} & \multicolumn{2}{|l|}{ Univariate } & \multicolumn{2}{|l|}{ Multivariate } \\
\hline Prognostic factor & Strata & Significance & $\operatorname{Exp}(B)(95 \%$ CI $)$ & Significance & $\operatorname{Exp}(B)(95 \% \mathrm{CI})$ \\
\hline Age & & 0.001 & $1.016(1.007-1.027)$ & 0.078 & $1.009(0.999-1.020)$ \\
\hline Sex & Female/male & 0.000 & $1.599(1.307-1.957)$ & 0.022 & $1.281(0.036-1.584)$ \\
\hline Timing & Metachronous/synchronous & 0.000 & $2.576(2.095-3.167)$ & 0.019 & $1.433(1.061-1.934)$ \\
\hline Disease-free interval & $>24$ months/0-24 months & 0.000 & $2.427(1.930-3.053)$ & 0.004 & $0.640(0.471-0.870)$ \\
\hline Number of liver metastases & Solitary/multiple & 0.000 & $2.215(1.787-2.745)$ & 0.000 & $1.614(1.265-2.060)$ \\
\hline Size of lesion & $\leq 5 \mathrm{~cm} />5 \mathrm{~cm}$ & 0.001 & $0.654(0.510-0.841)$ & 0.356 & $0.873(0.655-1.165)$ \\
\hline Extrahepatic disease & Absent/present & 0.000 & $0.585(0.478-0.716)$ & 0.911 & $1.015(0.776-1.329)$ \\
\hline Extent of liver resection & Limited/major & 0.000 & $1.640(1.265-2.128)$ & 0.955 & $1.009(0.738-1.379)$ \\
\hline Margin of liver resection & $\mathrm{R} 0 / \mathrm{R} 1-2$ & 0.000 & $2.451(1.963-3.059)$ & 0.000 & $1.814(1.359-2.421)$ \\
\hline \multirow[t]{3}{*}{$\mathrm{N}$-category of primary tumor } & $\mathrm{N} 0 / \mathrm{N}+/$ primary tumor not removed & 0.000 & & 0.265 & \\
\hline & & 0.073 & $1.239(0.980-1.565)$ & 0.623 & $1.063(0.833-1.356)$ \\
\hline & & 0.000 & $3.517(2.696-4.587)$ & 0.103 & $1.334(0.943-1.887)$ \\
\hline \multirow[t]{3}{*}{ Number of patients per hospital } & University $/>40$ patients $/ \leq 40$ patients & 0.000 & & 0.732 & \\
\hline & & 0.005 & $1.416(1.108-1.809)$ & 0.491 & $1.104(0.834-1.460)$ \\
\hline & & 0.000 & $1.810(1.396-2.347)$ & 0.457 & $1.127(0.823-1.543)$ \\
\hline
\end{tabular}

Bold indicates $p<0.005$ 
Table 6 Uni- and multi-variate analyses of patients with of breast or kidney carcinomas

\begin{tabular}{|c|c|c|c|c|c|}
\hline \multirow[t]{2}{*}{ Prognostic factor } & \multirow[t]{2}{*}{ Strata } & \multicolumn{2}{|l|}{ Univariate } & \multicolumn{2}{|l|}{ Multivariate } \\
\hline & & significance & $\operatorname{Exp}(B)(95 \%$ CI $)$ & significance & $\operatorname{Exp}(B)(95 \%$ CI $)$ \\
\hline \multicolumn{6}{|l|}{ Breast, $n=117$} \\
\hline Number of liver metastases & Solitary/multiple & 0.001 & $2.253(1.409-3.603)$ & 0.060 & $1.617(0.980-2.668)$ \\
\hline Size of lesion & $\leq 5 \mathrm{~cm} />5 \mathrm{~cm}$ & 0.076 & $1.547(0.955-2.506)$ & 0.267 & $1.321(0.808-2.158)$ \\
\hline Extrahepatic disease & Absent/present & 0.001 & $0.457(0.287-0.726)$ & 0.050 & $0.609(0.370-1.000)$ \\
\hline Margin of liver resection & $\mathrm{R} 0 / \mathrm{R} 1-2$ & 0.000 & $3.191(1.883-5.408)$ & 0.014 & $2.140(1.169-3.918)$ \\
\hline \multicolumn{6}{|l|}{ Kidney, $n=70$} \\
\hline Sex & Female/male & 0.186 & $1.590(0.800-3.161)$ & 0.371 & $1.404(0.668-2.951)$ \\
\hline Timing & Metachronous/synchronous & 0.016 & $2492(1.185-5.243)$ & 0.014 & $3.545(1.286-9.771)$ \\
\hline Disease-free interval & $>24$ months/0-24 months & 0.003 & $2.531(1.383-4.631)$ & 0.499 & $0.768(0.358-1.650)$ \\
\hline Number of liver metastases & Solitary/multiple & 0.004 & $2.588(1.343-4.985)$ & 0.015 & $2.597(1.208-5.584)$ \\
\hline Margin of liver resection & $\mathrm{R} 0 / \mathrm{R} 1-2$ & 0.004 & $2.430(1.325-4.455)$ & $\mathbf{0 . 0 3 5}$ & $2.045(1.051-3.979)$ \\
\hline
\end{tabular}

Bold indicates $p<0.005$

Table 7 Studies $>100$ patients with non-colorectal non-neuroendocrine liver metastasis since 2005

\begin{tabular}{|c|c|c|c|c|c|c|c|c|c|c|}
\hline & Period & $\begin{array}{l}\text { Num- } \\
\text { ber of } \\
\text { patients }\end{array}$ & $\begin{array}{l}\text { GIST } \\
\%\end{array}$ & $\begin{array}{l}\text { Melanoma } \\
\%\end{array}$ & $\begin{array}{l}\text { Sarcoma } \\
\%\end{array}$ & $\begin{array}{l}\text { Morbidity } \\
\text { (> Clavien 3) \% }\end{array}$ & $\begin{array}{l}30 \text {-day } \\
\text { mortal- } \\
\text { ity } \\
\%\end{array}$ & $\begin{array}{l}\text { R0 } \\
\%\end{array}$ & $\begin{array}{l}\text { 5-year } \\
\text { survival } \\
\%\end{array}$ & $\begin{array}{l}10 \text {-year } \\
\text { survival } \\
\%\end{array}$ \\
\hline Sano et al. (2018)* & $2001-2010$ & 1539 & 13 & 1 & $<1$ & 25 & 1.5 & 90 & 41 & 28 \\
\hline Adam et al. (2006)* & 1983-2004 & 1452 & 2 & 10 & 9 & 15 & 2.3 & 83 & 36 & 23 \\
\hline Groeschl et al. (2012)* & 1990-2009 & 420 & 0 & 7 & 23 & 20 & 1.9 & 81 & 31 & NR \\
\hline Schiergens et al. (2016) & 2003-2013 & 167 & 5 & 5 & 10 & 25 & 5 & 86 & 43 & 31 \\
\hline Hoffmann et al. (2015) & 2001-2012 & 150 & 7 & 10 & 6 & 26 & 0.7 & 80 & 42 & 27 \\
\hline Takemura et al. (2013) & 1993-2009 & 145 & 8 & $<1$ & 6 & 18 & 1.4 & 93 & 41 & NR \\
\hline Bohlok et al. (2020) & 2005-2017 & 114 & 0 & 4 & 10 & 11 & 0 & NR & 56 & 27 \\
\hline Holzner et al. (2018) & 1999-2015 & 100 & 12 & 14 & 6 & NR & NR & 90 & 57 & 34 \\
\hline Yedibela et al. (2005) & 1978- 2001 & 162 & 0 & 3 & 5 & 26 & 4 & 62 & 26 & NR \\
\hline O'rourke et al. (2008)* & 1986-2006 & 102 & 18 & 20 & 3 & 21 & 0.8 & 83 & 39 & NR \\
\hline Lendoire et al. (2007)* & 1989-2006 & 106 & 0 & 6 & 22 & NR & 1.8 & 90 & 19 & NR \\
\hline Slotta et al. (2014) & NR & 101 & 0 & 7 & 1 & 13 & 1 & NR & 30 & NR \\
\hline Present study* & $1995-2018$ & 637 & 3 & 5 & 5 & NR & 1.4 & 38 & 18 & 9 \\
\hline Present study R0-resected* & $1995-2018$ & 241 & 4 & 6 & 5 & 21 & 1.7 & 100 & 33 & 19 \\
\hline
\end{tabular}

*means multicentric study

Acknowledgements The authors gratefully acknowledge the support for this study from the Thüringische Gesellschaft für Chirurgie, and the cooperation of the following colleagues for their participation in data collection: Dr. med. Toralf Wolkersdörfer, Ilmkreis-Kliniken Arnstadt Ilmenau gGmbH, Dr. med. Rigo Voigt; Klinikum Altenburger Land GmbH, Dipl.-Med. Adnan Tofeili; KMG Klinik Bad Frankenhausen, Frau Anja Regel; Hufeland Klinikum Bad Langensalza, Dr. med. Cornelia Morgner, Helios Klinik Blankenhain, Univ.-Prof. Dr. med. W. Kneist; St. Georg Klinikum Eisenach gGmbH, Prof. Dr. med. Albrecht Stier Helios Klinik Erfurt, Prof. Dr. med. Yves Liebe SRH Wald-Klinikum Gera GmbH, Dr. med. Jörg Rose Helios Klinik Gotha, PD Dr. med. Olaf Guckelberger Helios Klinikum Meinigen, Dr. med. Peter Ihle Hufeland Klinikum Mühlhausen, PD Dr. med. Johann Hinnerk Gebhardt Südharz Klinikum Nordhausen, Dr. med. Hartmut Roth KMG Klinikum Sömmerda, Dr. med. Matthias Eichhorn REGIOMED Kliniken Sonneberg, Dr. med. Sabine Jeanette Presser, MBA M.Sc,
SRH Zentralklinikum Suhl, PD Dr. med. habil. Henning Mothes Klinikum Weimar Clinical Cancer Registry Thuringia with Tumor Center e.V. Erfurt Dr. med. Paul Strecker, UniversityTumorCenter University Hospital Jena Prof. Dr. med. Andreas Hochhaus, Tumor Center Nordhausen. Manuela Geist, Tumor Center Gera Uwe Funke and Tumor Center Suhl Matthias Wackes.

Funding Open Access funding enabled and organized by Projekt DEAL. Authors did not receive any funding/grants for this work.

\section{Declarations}

Conflict of interest The authors of this manuscript have no conflicts of interest to disclose. 
Open Access This article is licensed under a Creative Commons Attribution 4.0 International License, which permits use, sharing, adaptation, distribution and reproduction in any medium or format, as long as you give appropriate credit to the original author(s) and the source, provide a link to the Creative Commons licence, and indicate if changes were made. The images or other third party material in this article are included in the article's Creative Commons licence, unless indicated otherwise in a credit line to the material. If material is not included in the article's Creative Commons licence and your intended use is not permitted by statutory regulation or exceeds the permitted use, you will need to obtain permission directly from the copyright holder. To view a copy of this licence, visit http://creativecommons.org/licenses/by/4.0/.

\section{References}

Adam R, Chiche L, Aloia T et al (2006) Hepatic resection for noncolorectal nonendocrine liver metastases: analysis of 1,452 patients and development of a prognostic model. Ann Surg 244:524-535

Andreou A, Knitter S, Klein F et al (2018) The role of hepatectomy for synchronous liver metastases from pancreatic adenocarcinoma. Surg Oncol 27:688-694

Bauschke A, Altendorf-Hofmann A, Ali Deeb A, Kissler H, Tautenhahn HM, Settmacher U (2021) Surgical treatment of hepato-pancreatic metastases from renal cell carcinoma. Chirurg. https://doi. org/10.1007/s00104-020-01331-3

Bohlok A, Lucidi V, Bouazza F et al (2020) The lack of selection criteria for surgery in patients with non-colorectal non-neuroendocrine liver metastases. World J Surg Oncol 18:106

Dittmar Y, Altendorf-Hofmann A, Schule S et al (2013) Liver resection in selected patients with metastatic breast cancer: a singlecentre analysis and review of literature. J Cancer Res Clin Oncol 139:1317-1325

Feng Y, He XG, Zhou CM et al (2020) Comparison of hepatic resection and systemic treatment of breast cancer liver metastases: a propensity score matching study. Am J Surg 2020:940-951

Fritz AG (2013) International classification of diseases for oncology: ICD-O. 3rd edition, First revision. Aufl. World Health Organization, Geneva

Grimme FAB, Seesing MFJ, Van Hillegersberg R et al (2019) Liver resection for hepatic metastases from soft tissue sarcoma: a nationwide study. Dig Surg 36:479-486

Groeschl RT, Nachmany I, Steel JL et al (2012) Hepatectomy for noncolorectal non-neuroendocrine metastatic cancer: a multi-institutional analysis. J Am Coll Surg 214:769-777

Hackert T, Niesen W, Hinz U et al (2017) Radical surgery of oligometastatic pancreatic cancer. Eur J Surg Oncol 43:358-363

Hoffmann K, Bulut S, Tekbas A et al (2015) Is hepatic resection for non-colorectal, non-neuroendocrine liver metastases justified? Ann Surg Oncol 22(Suppl 3):S1083-1092

Holzner PA, Makowiec F, Klock A et al (2018) Outcome after hepatic resection for isolated non-colorectal, non-neuroendocrine liver metastases in 100 patients - the role of the embryologic origin of the primary tumor. BMC Surg 18:89

Jagric T, Horvat M (2020) Surgical resection of synchronous liver metastases in gastric cancer patients. A propensity score-matched study. Radiol Oncol 55:57

Kataoka K, Kinoshita T, Moehler M et al (2017) Current management of liver metastases from gastric cancer: what is common practice? New challenge of EORTC and JCOG. Gastric Cancer 20:904-912

Lendoire J, Moro M, Andriani O et al (2007) Liver resection for noncolorectal, non-neuroendocrine metastases: analysis of a multicenter study from Argentina. HPB (Oxf) 9:435-439
Lu T, Yang X, Huang Y et al (2019) Trends in the incidence, treatment, and survival of patients with lung cancer in the last four decades. Cancer Manag Res 11:943-953

Lucchese AM, Kalil AN, Ruiz A et al (2018) Neoadjuvant chemotherapy response influences outcomes in non-colorectal, nonneuroendocrine liver metastases. Br J Surg 105:1665-1670

Luo Z, Rong Z, Huang C (2019) Surgery strategies for gastric cancer with liver metastasis. Front Oncol 9:1353

Millen JA, Hofmann A, Mesquita-Neto JW et al (2021) Evolving role of liver resection in selected patients with metastatic breast cancer. J Surg Res 259:363-371

O'rourke TR, Tekkis P, Yeung S et al (2008) Long-term results of liver resection for non-colorectal, non-neuroendocrine metastases. Ann Surg Oncol 15:207-218

Ruys AT, Tanis PJ, Nagtegaal ID et al (2011) Surgical treatment of renal cell cancer liver metastases: a population-based study. Ann Surg Oncol 18:1932-1938

Sadot E, Lee SY, Sofocleous CT et al (2016) Hepatic resection or ablation for isolated breast cancer liver metastasis: a case-control study with comparison to medically treated patients. Ann Surg 264:147-154

Sano K, Yamamoto M, Mimura T et al (2018) Outcomes of 1,639 hepatectomies for non-colorectal non-neuroendocrine liver metastases: a multicenter analysis. J Hepatobiliary Pancreat Sci 25:465-475

Schiergens TS, Luning J, Renz BW et al (2016) Liver resection for non-colorectal non-neuroendocrine metastases: where do we stand today compared to colorectal cancer? J Gastrointest Surg 20:1163-1172

Schmelzle M, Eisenberger CF, Am Esch JS et al (2010) Non-colorectal, non-neuroendocrine, and non-sarcoma metastases of the liver: resection as a promising tool in the palliative management. Langenbecks Arch Surg 395:227-234

Slotta JE, Schuld J, Distler S et al (2014) Hepatic resection of noncolorectal and non-neuroendocrine liver metastases-survival benefit for patients with non-gastrointestinal primary cancers-a case-controlled study. Int J Surg 12:163-168

Stegmaier C, Hentschel S, Hofstädter F, Katalinic A, Tillack A, Klinkhammer-Schalke M (eds) (2019) Das Manual der Kebsregistrierung. W. Zuckschwerdt Verlag GmbH für Medizin u. Naturwissensch, München (ISBN: 978-3-86371-165-8)

Tachezy M, Gebauer F, Janot M et al (2016) Synchronous resections of hepatic oligometastatic pancreatic cancer: Disputing a principle in a time of safe pancreatic operations in a retrospective multicenter analysis. Surgery 160:136-144

Takemura N, Saiura A, Koga R et al (2013) Long-term results of hepatic resection for non-colorectal, non-neuroendocrine liver metastasis. Hepatogastroenterology 60:1705-1712

Weitz J, Blumgart LH, Fong Y et al (2005) Partial hepatectomy for metastases from noncolorectal, nonneuroendocrine carcinoma. Ann Surg 241:269-276

Yedibela S, Gohl J, Graz V et al (2005) Changes in indication and results after resection of hepatic metastases from noncolorectal primary tumors: a single-institutional review. Ann Surg Oncol $12: 778-785$

Zhuo S, Zhou J, Ruan G et al (2020) Percutaneous microwave ablation versus surgical resection for ovarian cancer liver metastasis. Int $\mathbf{J}$ Hyperthermia 37:28-36

Publisher's Note Springer Nature remains neutral with regard to jurisdictional claims in published maps and institutional affiliations. 